Article

\title{
Structure-Activity Relationship of the Tyrosinase Inhibitors Kuwanon G, Mulberrofuran G, and Albanol B from Morus Species: A Kinetics and Molecular Docking Study
}

\author{
Prashamsa Koirala ${ }^{1}$, Su Hui Seong ${ }^{1}$, Yajuan Zhou ${ }^{1}$, Srijan Shrestha ${ }^{1}$, Hyun Ah Jung ${ }^{2, *}$ \\ and Jae Sue Choi ${ }^{1, *(\mathbb{D})}$ \\ 1 Department of Food and Life Science, Pukyong National University, Busan 48513, Korea; \\ prashamsakoirala20@gmail.com (P.K.); seongsuhui@naver.com (S.H.S.); zhouyajuan26@gmail.com (Y.Z.); \\ srijanstha003@gmail.com (S.S.) \\ 2 Department of Food Science and Human Nutrition, Chonbuk National University, Jeonju 54896, Korea \\ * Correspondence: jungha@jbnu.ac.kr (H.A.J.); choijs@pknu.ac.kr (J.S.C.); Tel.: +82-63-270-4882 (H.A.J.); \\ +82-51-629-5845 (J.S.C.)
}

Received: 1 May 2018; Accepted: 9 June 2018; Published: 11 June 2018

\begin{abstract}
Kuwanon $G(K G)$ and benzofuran flavonoids such as mulberrofuran $G(M G)$ and albanol $\mathrm{B}(\mathrm{AB})$ isolated from Morus sp. are reported to exhibit anti-Alzheimer's disease, anti-inflammatory, fungicidal, anti-cancer, anti-bacterial, and anti-tyrosinase properties. We investigated the inhibition of mono- and diphenolase activity of mushroom tyrosinase by KG, MG, and AB. KG and MG displayed acceptable inhibition activity compared to kojic acid. $\mathrm{AB}$ did not show any activity up to $350 \mu \mathrm{M}$. MG displayed six-fold higher inhibition of L-tyrosine oxidation $\left(\mathrm{IC}_{50}=6.35 \pm 0.45 \mu \mathrm{M}\right)$ compared to kojic acid $\left(\mathrm{IC}_{50}=36.0 \mu \mathrm{M}\right)$. Kinetic studies revealed that $\mathrm{KG}$ and MG inhibited monophenolase activity of tyrosinase in a competitive manner. Docking simulations of KG and MG demonstrated favorable binding energies with amino acid residues of the active sites of tyrosinase. Our investigation of the structure-activity relationship of the fused benzofuran flavonoids (MG vs. $\mathrm{AB}$ ) implicated the methyl cyclohexene ring moiety in tyrosinase inhibition. The enzyme substrate and relative structural analyses demonstrated that KG and MG from Morus sp. could be useful natural tyrosinase inhibitors in foods or cosmetics.
\end{abstract}

Keywords: Morus species; mulberrofuran G; kuwanon G; albanol B; mushroom tyrosinase; structure-activity relationship

\section{Introduction}

Tyrosinase is a ubiquitous enzyme in micro-organisms, animals, and plants. The oxidation of L-tyrosine and L-3,4-dihydroxyphenylalanine (L-DOPA) are rate-limiting steps in the melanin formation pathway mediated by tyrosinase. These steps are crucial for skin protection against UV damage. Functional deficiencies of this pathway can result in serious dermatological diseases. Mushroom tyrosinase is a commercially available tyrosinase that has high homology with mammalian tyrosinase. Tyrosinase inhibitors are vital in the food industry [1].

Mulberry species, genus Morus L. of the family Moraceae, are widely distributed. Fourteen species have been reported and classified by Zeng et al. [2] and are widespread in the sub-tropical regions of Asia such as Japan, India, China, and Korea. The leaves are eaten by silkworms (Bombyx mori L.), are used in Chinese herbal tea [3], and are considered potent due to the presence of steroids, terpenoids, saponins, alkaloids, flavonoids, and tannins [4]. The ripe fruit is edible and used in pies, tarts, 
wines, cordials, and herbal teas. The leaves are sold in various forms as nutritional supplements. The mature plant contains significant amounts of resveratrol, particularly in the stem bark [5]. The leaf, root bark, and fruit of the mulberry plant have an extensive history in traditional Chinese medicine. Various food products containing mulberry leaves, such as mulberry tea, are used in many countries [6]. Mulberry has a long history as a conventional medicinal herb due to its chemical composition and pharmacological functions. Anti-diabetic [7], cardioprotective [6], antifungal [8], antioxidant [9], hepatoprotective [10], and cytotoxic activities [11] have been reported from Morus species.

The tyrosinase inhibitory activity of kuwanon $\mathrm{G}(\mathrm{KG})$ is unclear [12,13], but it has displayed antioxidant [14], antibacterial [15], cosmetic [13], anti-Alzheimer's disease [16], anti-inflammatory [17, 18], and anti-asthmatic [19] properties. Mulberrofuran G (MG) from Morus exhibited antibacterial [20], antioxidant [21], and hepatoprotective [22] activities, cosmetic value, and tyrosinase inhibition activity [12]. Albanol B (AB) has also demonstrated anti-Alzheimer's disease [16], antibacterial [23], and antioxidant [5] activities. Tyrosinase inhibition studies have been conducted in Morus australis [24] and Morus nigra [12]. Morus australis was previously investigated as an anti-obesity [25] and skin whitening [26] agent. Oxyresveratrol was the prime component [24] along with anthocyanins [25], phenolic compounds [27], and flavonoids [28]. Morus nigra contains phenolic compounds, including oxyresveratrol and mulberroside A [12], with neuroprotective [29], antioxidant, antibacterial, and cytotoxic activities [30].

Structure-activity relationship (SAR) studies can assist in identifying active moieties for the development of novel drugs. For this, it is necessary to understand the reaction mechanism. Chao et al. [31] demonstrated the effects of essential oils comprising a methyl cyclohexene ring on melanin content and cellular tyrosinase activity, which supported our investigation of this particular moiety.

Our study mechanistically investigated the reason behind the conflicting tyrosinase inhibitory activity of KG through monophenolase and diphenolase inhibitory assays with L-tyrosine and L-DOPA as a substrate, respectively [12]. In addition, SAR analysis as well as kinetics and molecular docking studies were used to characterize the interaction of KG, MG, and AG from Morus species with tyrosinase for the first time.

\section{Results}

\subsection{Inhibitory Activities of $K G, M G, A B$ and 1-Methyl-1-Cyclohexene on Mushroom Tyrosinase} (L-Tyrosine and L-DOPA Substrates)

Three compounds from Morus species (Figure 1) were tested for their tyrosinase inhibitory activity with L-tyrosine (Table 1). MG had an $\mathrm{IC}_{50}$ value of $6.35 \mu \mathrm{M}$ and exhibited five times greater tyrosinase inhibitory activity compared to kojic acid $\left(\mathrm{IC}_{50}=36.02 \mu \mathrm{M}\right)$. $\mathrm{AB}$ was found to be inactive. $\mathrm{KG}$ displayed significant tyrosinase inhibitory activity with an $\mathrm{IC}_{50}$ value of $67.6 \mu \mathrm{M}$ (Figure 2). KG showed potent activity toward L-DOPA with an $\mathrm{IC}_{50}$ value of $44.04 \mu \mathrm{M}$, which was almost twice that of the positive control $\left(\mathrm{IC}_{50}=79.0 \mu \mathrm{M}\right)$. MG showed an acceptable $\mathrm{IC}_{50}$ value of $105.57 \mu \mathrm{M}$, while $\mathrm{AB}$ was inactive. Likewise, 1-methyl-1-cyclohexene moiety itself was inactive regarding both assays ( $\mathrm{IC}_{50}>1000 \mu \mathrm{M}$ ). However, our result for inhibition of mushroom tyrosinase by KG was significantly different from that of Zheng et al. [12] who demonstrated that KG showed no activity up to $200 \mu \mathrm{M}$ against monophenolase. Thus, we further studied kinetic and molecular docking analysis to confirm our results. 


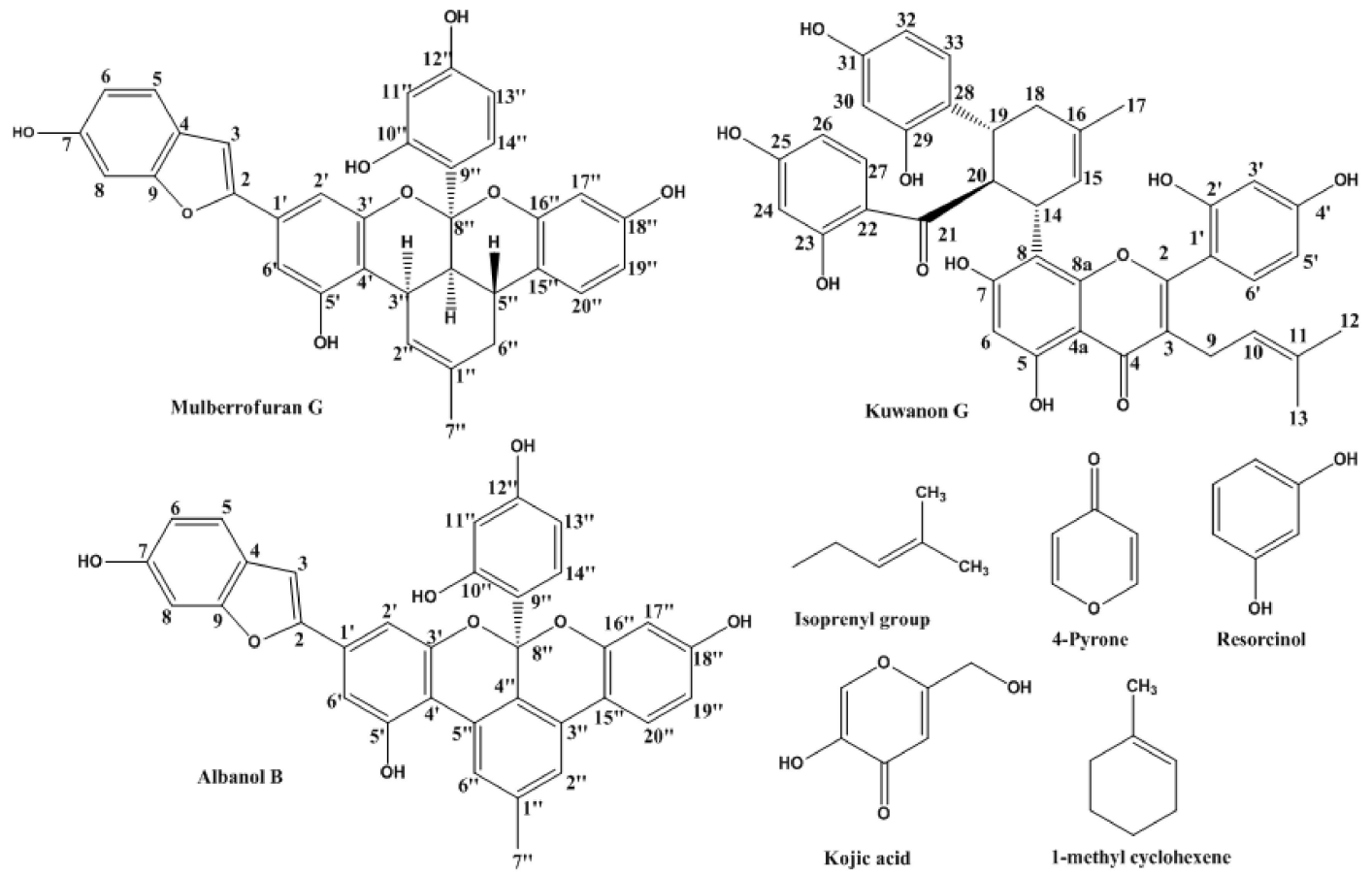

Figure 1. Structure of compounds from Morus species and structural moieties explaining structureactivity relationship.

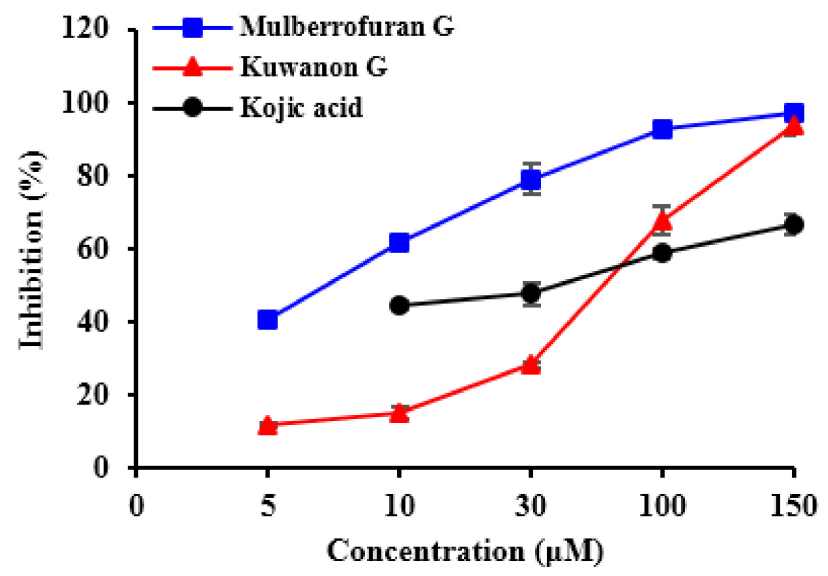

Figure 2. Concentration-dependent inhibition of kuwanon $G$, mulberrofuran $G$, and kojic acid on the activity of tyrosinase for the catalysis of L-tyrosine at $25^{\circ} \mathrm{C}$.

Table 1. Inhibitory activities of the compounds isolated from the root bark of Morus alba on mushroom tyrosinase.

\begin{tabular}{|c|c|c|c|c|}
\hline \multirow{2}{*}{ Compounds } & \multicolumn{2}{|c|}{$\mathrm{IC}_{50}(\mu \mathrm{M})$ Value $^{\mathrm{a}}$} & \multirow{2}{*}{ Inhibition Mode ${ }^{b}$} & \multirow{2}{*}{ Inhibition Constant $\left(K_{i}, \mu \mathrm{M}\right)$} \\
\hline & L-Tyrosine & L-DOPA & & \\
\hline Kuwanon G & $67.6 \pm 2.11$ & $44.0 \pm 3.73$ & Competitive & 18.7 \\
\hline Mulberrofuran G & $6.35 \pm 0.45$ & $105.6 \pm 1.85$ & Competitive & 5.19 \\
\hline 1-Methyl-1-cyclohexene & $>1000$ & $>1000$ & $\mathrm{NT}^{\mathrm{e}}$ & NT \\
\hline Albanol B & $>350$ & $>350$ & NT & NT \\
\hline Kojic acid ${ }^{d}$ & $36.0 \pm 0.88$ & $79.0 \pm 0.06$ & NT & NT \\
\hline
\end{tabular}

${ }^{\text {a }}$ The $50 \%$ inhibition concentration $(\mu \mathrm{M})$ is calculated from a log-dose inhibition curve and expressed as the mean \pm SEM of triplicate experiments. ${ }^{b}$ Determined by Lineweaver-Burk plot. ${ }^{c}$ Determined by Dixon plot.

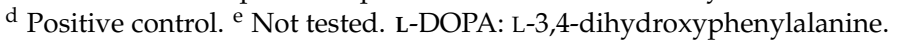




\subsection{Enzyme Kinetic Analysis of KG and MG with Monophenolase Activity of Tyrosinase}

Kinetic analysis was employed to verify the inhibitory activity of the active compounds and identify the type of inhibition. KG and MG were potent tyrosinase inhibitors as analyzed by Lineweaver-Burk and Dixon plots (Figures 3 and 4). Different concentrations of the substrate (L-tyrosine, 1.0, 0.5, and $0.25 \mathrm{mM}$ ) along with the various concentrations of $\mathrm{KG}(10,50$, and $100 \mu \mathrm{M})$ and MG $(1.6,8$, and $40 \mu \mathrm{M})$ were analyzed. The lines of the Dixon plot intersected the y-intercept, which indicated competitive inhibition of tyrosinase with $K_{i}$ values of 18.66 and 5.19, respectively, for KG and MG (Table 1). The $K_{i}$ values represent the concentrations required to form an enzyme inhibitor complex, so inhibitors with lower $K_{i}$ values indicate greater tyrosinase inhibition activity for the development of prophylactic and therapeutic agents.
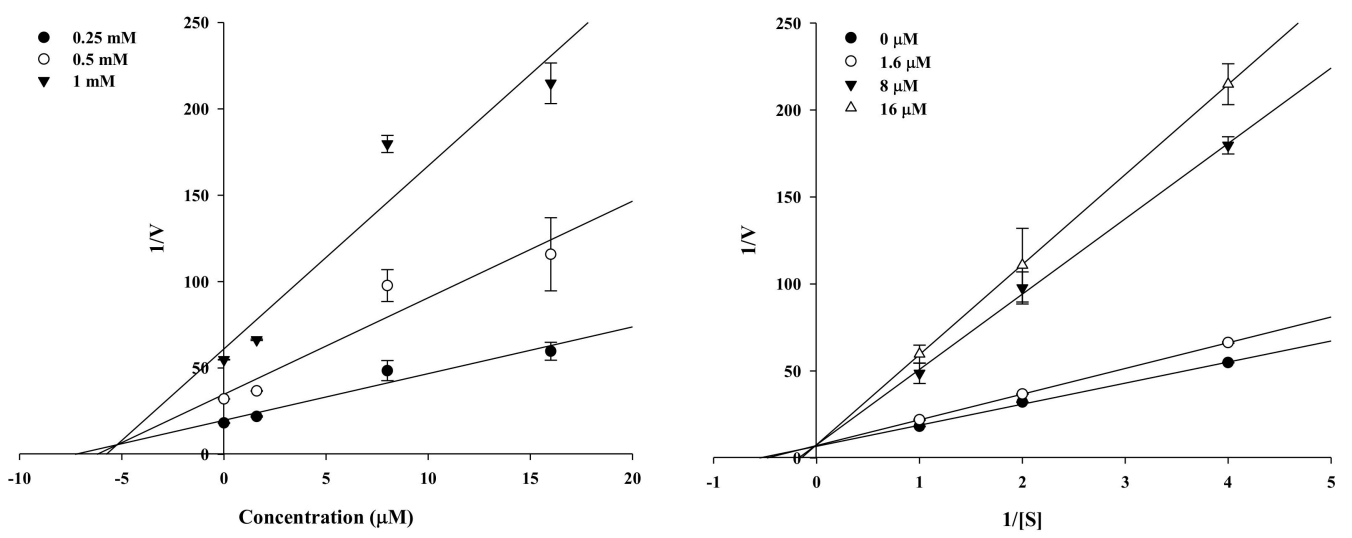

Figure 3. Dixon plots and Lineweaver-Burk plots for mushroom tyrosinase inhibition of mulberrofuran G.
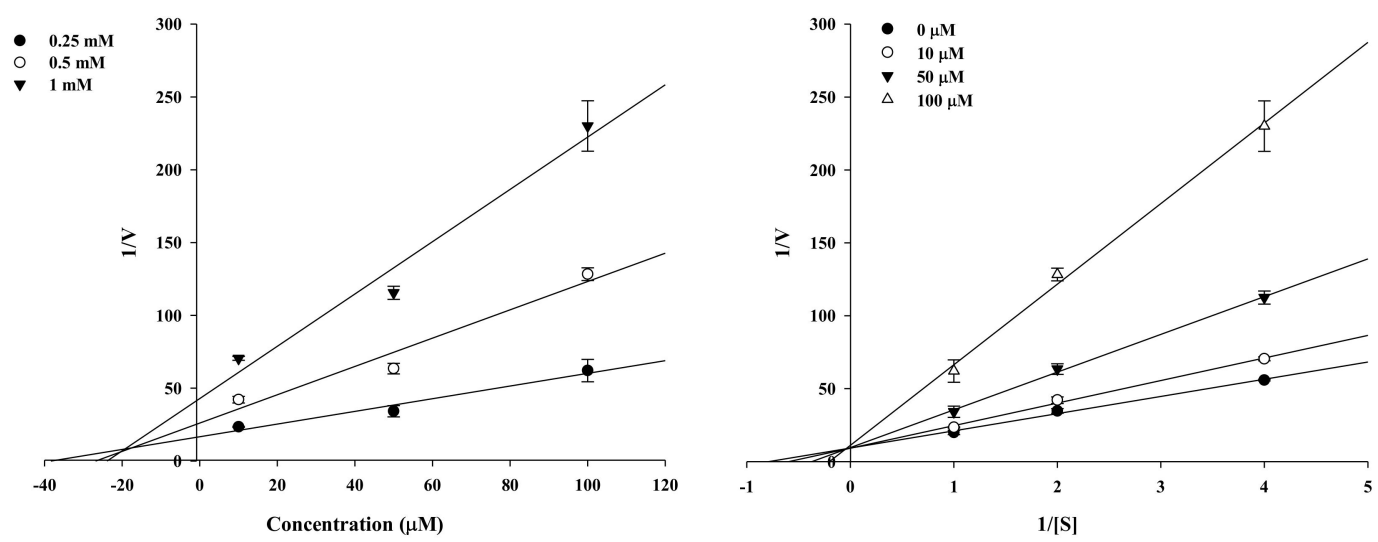

Figure 4. Dixon plots and Lineweaver-Burk plots for mushroom tyrosinase inhibition of kuwanon G.

\subsection{Molecular Docking Simulation of KG, MG and AB Tyrosinase Inhibition}

The enzyme kinetic results indicated that both KG and MG are competitive inhibitors of mushroom tyrosinase. We performed the molecular docking simulation using AutoDock 4.2 to understand the inhibition mechanism of KG and MG. Kojic acid has been used as a selective competitive inhibitor in several studies [31-33], but the allosteric inhibition mechanism toward tyrosinase is unclear. Hassani et al. [34] recently reported cinnamic acid as a mixed type inhibitor that interacted with secondary binding sites when the catalytic pocket was occupied with tropolone (co-ligand of 2Y9X). L-Tyrosine, kojic acid, and cinnamic acid were used to validate our docking results.

As shown in Figure 5 and Table 2, MG-enzyme complex showed a low binding energy in the catalytic site of oxy-form mushroom tyrosinase $(-7.60 \mathrm{kcal} / \mathrm{mol})$. Two hydrogen bonds were 
formed between two -OH groups of MG and Arg268 and Val283 residues in the protein-MG complex (Figure 5B,E). In addition, MG interacted with the two peroxide ions via hydrogen bonding interactions (distance: 1.77 and $2.96 \AA$ ). In case of protein-KG complex (Figure 5A,D), four hydrogen bonds were observed between -OH groups of KG and Val283, His263, Gly281, and Ser282 residues of enzyme. KG also hydrogen bonded with two peroxide ions (distance: 2.04 and $2.94 \AA$ ). Because peroxide ions are important targets for inhibition of oxy-form tyrosinase, MG showed more high binding affinity than KG based on H-bond distance. In addition, two copper ions interacted with MG and KG via van der Waals interactions. We also investigated the interactions between $\mathrm{AB}$ and mushroom tyrosinase. Although $\mathrm{AB}$ reach to catalytic site of enzyme and possesses the low binding energy $(-7.28 \mathrm{kcal} / \mathrm{mol})$, $\mathrm{AB}$ could not interacted with copper and peroxide ions. The methyl cyclohexene moiety of KG and MG formed multiple hydrophobic interactions with crucial residues, whereas the methyl benzene ring of $A B$ weakly interacted with the Val248 residue via Pi-alkyl interaction. These in silico computational docking results could explain why the $\mathrm{IC}_{50}$ values of $\mathrm{MG}$ and $\mathrm{KG}$ were lower than that of $\mathrm{AB}$ and supported the in vitro experimental kinetic results, which revealed that KG and MG were competitive inhibitors of mushroom tyrosinase.

A

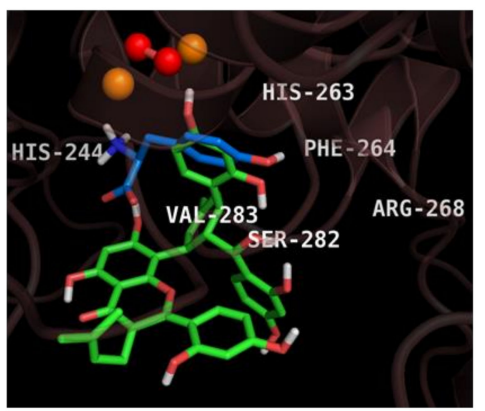

B

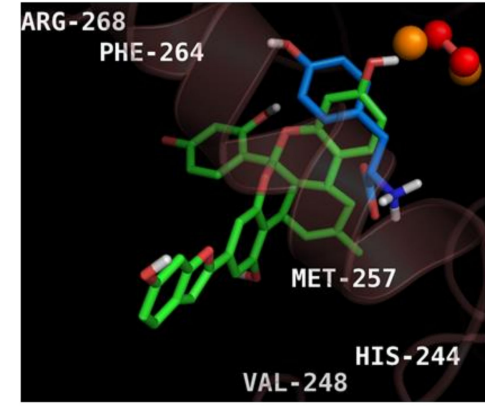

C

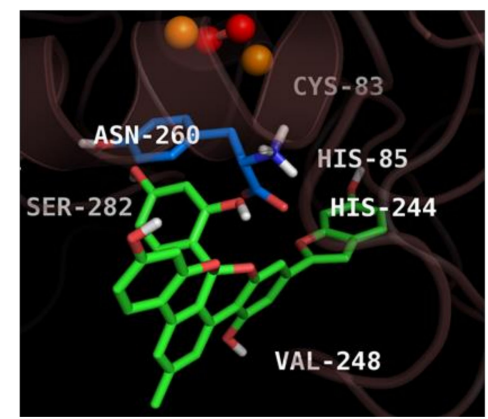

$\mathrm{D}$

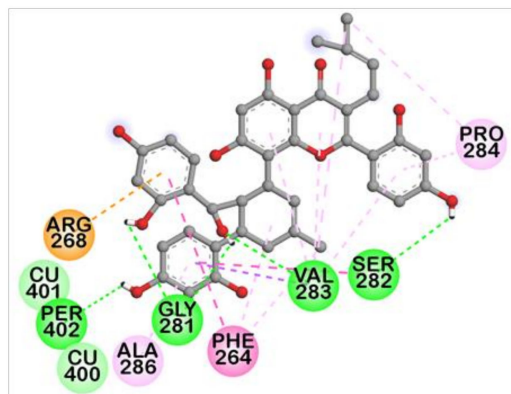

$\mathrm{F}$

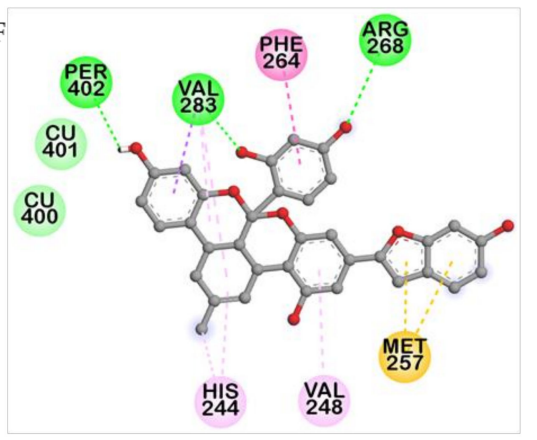

F

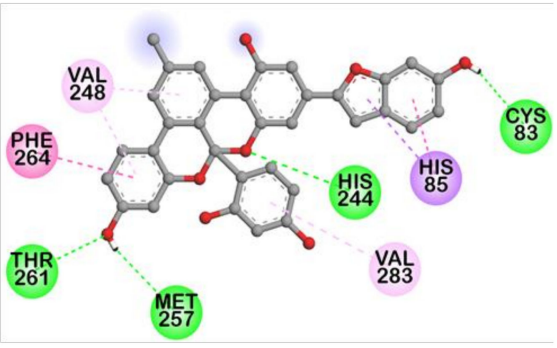

Figure 5. Inhibition mode of kuwanon $G(A)$, mulberrofuran $G(B)$, and albanol B (C) for the oxy-form mushroom tyrosinase catalytic site with L-tyrosine (blue stick). Two copper ions and peroxide ions are represented as orange and red spheres, respectively. Tested inhibitors are represented in green stick. 2D diagram of tyrosinase inhibition by kuwanon $G(\mathbf{D})$, mulberrofuran $G(E)$, and albanol B (F). 
Table 2. Molecular interaction of oxy-form mushroom tyrosinase active site with three compounds as well as positive controls.

\begin{tabular}{|c|c|c|c|c|c|}
\hline Compounds & $\begin{array}{l}\text { Binding Energy } \\
\text { (Kcal/mol) }\end{array}$ & $\begin{array}{c}\text { H-Bond } \\
\text { Interaction }\end{array}$ & $\begin{array}{l}\text { Van der Waals } \\
\text { Interaction }\end{array}$ & Hydrophobic Interaction & Others \\
\hline Kuwanon G & -6.95 & $\begin{array}{l}\text { Per402, Val283, } \\
\text { His263, Gly281, } \\
\text { Ser282 }\end{array}$ & $\mathrm{Cu} 400, \mathrm{Cu} 401$ & $\begin{array}{c}\text { Pi-sigma: Val283 } \\
\text { Pi-Pi Stacked: His263 } \\
\text { Pi-Pi T-Shaped: Phe264 } \\
\text { Amide-Pi Stacked: Val283, } \\
\text { Ser282 } \\
\text { Alkyl: Val283, Pro284 } \\
\text { Pi-Alkyl: Phe264, Val283, } \\
\text { Pro284, Ala286 }\end{array}$ & $\begin{array}{l}\text { Pi-Cation: } \\
\text { Arg268 }\end{array}$ \\
\hline Mulberrofuran G & -7.60 & $\begin{array}{c}\text { Per402, Arg268, } \\
\text { Val283 }\end{array}$ & Cu400, Cu401 & $\begin{array}{c}\text { Pi-sigma: Val283 } \\
\text { Pi-Pi T-Shaped: Phe264 } \\
\text { Alkyl: Val283 } \\
\text { Pi-Alkyl: His244, Val248 }\end{array}$ & $\begin{array}{l}\text { Pi-Sulfur: } \\
\text { Met257 }\end{array}$ \\
\hline Albanol B & -7.28 & $\begin{array}{l}\text { Cys83, His244, } \\
\text { Met257, Thr261 }\end{array}$ & - & $\begin{array}{c}\text { Pi-Sigma: His85 } \\
\text { Pi-Pi T-shaped: His85, } \\
\text { Phe264 } \\
\text { Pi-Alkyl: Val248, Val283 }\end{array}$ & - \\
\hline L-Tyrosine ${ }^{a}$ & -6.31 & $\begin{array}{l}\text { His244, Asn260, } \\
\text { Met280, Glu256 } \\
\text { (Salt-bridge) }\end{array}$ & $\begin{array}{l}\text { Per402, Cu400, } \\
\text { Cu401 }\end{array}$ & $\begin{array}{c}\text { Pi-Sigma: Val283 } \\
\text { Pi-Pi Stacked: His263 } \\
\text { Pi-Alkyl: Ala286 }\end{array}$ & - \\
\hline Kojic acid ${ }^{b}$ & -5.5 & Met280 & $\mathrm{Cu} 400, \mathrm{Cu} 401$ & $\begin{array}{c}\text { Pi-Sigma: Val283 } \\
\text { Pi-Pi T-Shaped: His263 } \\
\text { Pi-Alkyl: Ala286 }\end{array}$ & \\
\hline Cinnamic acid ${ }^{b, c}$ & -6.20 & $\begin{array}{c}\text { Gln307, } \\
\text { Asp312, Glu356 }\end{array}$ & Tyr314 & Pi-Pi Stacked: Trp358 & - \\
\hline
\end{tabular}

${ }^{a}$ Reported competitive ligand. ${ }^{b}$ Reported competitive type inhibitor. ${ }^{b}$ Reported mixed type inhibitor. ${ }^{c}$ Interaction of cinnamic acid to allosteric site, while troplone (co-ligand of 2Y9X) is sited in catalytic pocket.

\section{Discussion}

Tyrosinase is a rate-limiting, copper-containing enzyme that controls the production of melanin in the human body, which can lead to a variety of skin disorders when overproduced [35]. Many natural compounds including quercetin, hydroquinone, chalcones, stilbenes, kojic acid, aloesin, and coumarins have been reported as tyrosinase inhibitors [36]. The present investigation is the first report of MG and $\mathrm{AB}$ for enzyme kinetics and molecular docking analysis against mushroom tyrosinase. The inhibitory kinetics and binding mechanisms of $\mathrm{KG}, \mathrm{MG}$, and $\mathrm{AB}$ from Morus species were determined through molecular docking analysis using oxy-form mushroom tyrosinase. Our molecular and structural results clarify the tyrosinase inhibition mechanism of $K G$ and support potential for cosmetic use via tyrosinase inhibition. KG and MG displayed potent inhibitory activity against mono- and diphenolase activity compared to kojic acid. AB did not show any activity, even at a high concentration $(350 \mu \mathrm{M})$.

$K G, M G$, and $A B$ have recently attracted extensive research focus. We systematically investigated these three compounds as potential candidates against Alzheimer's disease [16]. As a part of our ongoing research, we designed L-tyrosine and L-DOPA oxidation assays to investigate the inhibition activity of these compounds against mushroom tyrosinase. L-Tyrosine and L-DOPA are consecutive substrates, inducers, and positive regulators of melanogenesis that can regulate melanocyte function through overlapping pathways [37]. Differences among the inhibition activities of these two substrates can be explained by the specific binding properties between the enzyme and substrate. Zheng et al. [12] determined that L-tyrosine oxidation was inhibited by $\mathrm{MG}\left(\mathrm{IC}_{50}=17.53 \mu \mathrm{M}\right)$, which was consistent with our results. In addition to a positive trend, MG was two times more potent than the result obtained in our current study. Slight variation can be attributed to experimental-setup errors. KG showed potent inhibition towards L-tyrosine in our study $\left(\mathrm{IC}_{50}=67.6 \mu \mathrm{M}\right)$, despite being previously reported as inactive up to $200 \mu \mathrm{M}$ [12]. Our study refuted this result by providing chemical kinetics and molecular docking data. Chaita et al. [13] also reported that KG showed potent mushroom tyrosinase inhibitory activity $\left(\mathrm{IC}_{50}=27.2 \mu \mathrm{M}\right)$ via the L-DOPA pathway. These results are in close agreement with our present study $\left(\mathrm{IC}_{50}=44.0 \mu \mathrm{M}\right)$. 
Molecular mechanistic studies confirmed the tyrosinase inhibition activity of KG and MG via the L-tyrosine pathway. The respective double reciprocal Lineweaver-Burk plot revealed the competitive inhibition mechanism of KG and MG, and that both compounds readily bound to the catalytic site. MG had a greater binding affinity than KG as indicated by the lower $K_{i}$ value of 5.93 . For these types of inhibitors, a higher substrate concentration is needed to achieve $50 \%$ occupation of the active sites. Kinetic studies revealed that both compounds were competitive inhibitors, indicating that they bind to the enzyme-substrate complex or interact with a specific catalytic site of the enzyme.

Molecular docking studies model the interaction between a small molecule and a protein at an atomic level, which allows characterization of small molecule behavior in the binding site of target proteins and elucidation of fundamental biochemical processes. The binding interactions of MG, KG, and $\mathrm{AB}$ from Morus species were indicative of tyrosinase inhibition activity. AB had a smaller docking score than kojic acid, but the lack of interactions with copper and peroxide ions and catalytic residues of tyrosinase limited the inhibitory activity. On the other hand, MG and KG interacted with two copper ions and peroxide ions via van der Waals interaction and $\mathrm{H}$-bond, respectively. Multiple hydrophobic interactions were also observed in the protein-KG and -MG complexes. Interestingly, the methyl cyclohexene moiety of KG and MG formed multiple hydrophobic interactions with enzyme residues, whereas the methyl benzene ring of $\mathrm{AB}$ weakly hydrophobic interacted with the Val248 residue of enzyme. This is the first report of tyrosinase inhibition activity of MG and KG supported by enzyme kinetic analysis and molecular docking simulation.

Structure-activity relationships might explain the variable activities observed in these flavonoids. We studied the roles of methyl benzene, resorcinol, isoprenyl, and 4-pyrone moieties, focusing on the methyl cyclohexene ring structure. KG is a prenylated flavonoid, while MG and AB are fused benzofurans with specific roles. Zheng et al. [12] demonstrated the importance of isoprenyl moiety, where Kuwanon $\mathrm{H}$ contains one additional isoprenyl moiety which attributed to the improved activity as compared to KG. Our study, on the other hand, was not in accordance to this hypothesis, where MG is devoid of isoprenyl moiety, but showed better activity despite the lack of isoprenyl moiety in MG, better monophenolase inhibitory activity than the monoisoprenyl substituted flavone KG.

In another case, previous studies have suggested that the presence of resorcinol moiety in prenylated flavonoids is responsible for the activity. Major compounds kurarinol and kuraridinol from Sophora flavescens showed tyrosinase inhibitory activity that was attributed to the resorcinol moiety [38]. The results of our tyrosinase inhibitory assay on the prenylated flavonoid (KG) and fused benzofuran flavonoids (MG and $\mathrm{AB}$ ) contradicted their hypothesis. While four resorcinol moieties should have increased the activity of the prenylated fused flavonoid KG, the non-prenylated MG with only one resorcinol group was more active. $\mathrm{AB}$ on the other hand was also unable to deliver the tyrosinase inhibitory activity, regardless the presence of resorcinol group. Nevertheless, the presence of resorcinol moiety cannot be undermined since the docking study on KG suggested that resorcinol moiety is vital for the activity as it forms a hydrogen bond with GLU 322 which is difficult to break due to hydrophobic interactions. Undoubtedly, resorcinol moiety has been a prime focus since long time, but herein we were compelled to present the additional probability of methyl cyclohexene moiety for the tyrosinase activity. $\mathrm{AB}$ comprising methyl benzene moiety in its structure in the catalytic site is unable to bind to the crucial surrounding residues, designating it inactive against tyrosinase inhibition, while the methyl cyclohexene pendant of compounds like KG and MG occupies the catalytic site resulting in the proper orientation with the residues vital for the activity. This fact also explains the reason for the activity of $\mathrm{AB}, \mathrm{KG}$, and MG.

Our study suggested that the methyl cyclohexene ring was responsible for inhibitory action against tyrosinase, which is an established hypothesis. The recent evaluation of the essential oils $\alpha$-pinene and $\alpha$-terpineol for tyrosinase and melanogenesis inhibition demonstrated positive results [31]. Methyl cyclohexene is a major functional group of $\alpha$-pinene and $\alpha$-terpineol and was highly active. This result supported our evidence of the activity of this moiety that is ubiquitous in essential oils. $\beta$-caryophyllene from lime mint oil, comprised of the same methyl cyclohexene group, has shown 
potent skin whitening effects. At $150 \mu \mathrm{M}, \beta$-caryophyllene decreased intracellular tyrosinase activity in B16F10 cells [39]. These results suggest that the methyl cyclohexene group is responsible for tyrosinase inhibitory activity rather than the isoprenyl or resorsinol group itself.

$\mathrm{AB}$ has a methyl benzene ring in place of methyl cyclohexene, which explains its inactivity. Benzene has a resonance structure that leads to this inactivity: a large activation energy is required to break the double bonds of unsaturated hydrocarbons. The three double bonds of benzene are delocalized in a pi-system, so a low electron density results in low reactivity. MG forms bonds readily via a methyl cyclohexene functional group instead of a benzene group, which explains the tyrosinase inhibitory activity. The methyl cyclohexene moiety in KG also demonstrated acceptable inhibitory activity. KG has a similar structure to kojic acid, which contains 4-pyrone and might also contribute to its inhibitory activity. Our study supports the functionality of methyl cyclohexene in tyrosinase inhibition.

\section{Materials and Methods}

\subsection{Chemicals/Reagents and Compounds}

$\mathrm{KG}, \mathrm{MG}$, and $\mathrm{AB}$ were obtained from the root bark of Morus alba by Kuk et al. [16] as previously described. L-DOPA, kojic acid, and mushroom tyrosinase were purchased from Sigma-Aldrich Co. (St. Louis, MO, USA). L-Tyrosine was purchased from Jannssen Chimica (Geel, Belgium). $\mathrm{K}_{2} \mathrm{HPO}_{4}$ was obtained from Junsei Chemical Co. Ltd. (Tokyo, Japan), and $\mathrm{KH}_{2} \mathrm{PO}$ was acquired from Yakuri Pure Chemicals Co. Ltd. (Osaka, Japan). Reagent-grade chemicals and solvents were purchased from commercial sources. Ultra-pure water was used throughout the experiment.

\subsection{Mushroom Tyrosinase Inhibitory Assay}

We investigated the L-DOPA and L-tyrosine oxidization activity of KG, MG, and AB isolated from root bark of Morus alba in our previous study with a modified spectrophotometric method [40,41]. Briefly, $10 \mu \mathrm{L}$ of a specified concentration of each sample solution $(1-500 \mu \mathrm{g} / \mathrm{mL})$ in $10 \%$ dimethyl sulfoxide and $20 \mu \mathrm{L}$ of mushroom tyrosinase (1000 Units/mL) in a $50 \mathrm{mM}$ phosphate buffer $(\mathrm{pH}$ 6.5) were added to $170 \mu \mathrm{L}$ of an assay mixture in a 96-well microplate. The ratio of $1 \mathrm{mM}$ L-tyrosine/ L-DOPA solution, $50 \mathrm{mM}$ potassium phosphate buffer ( $\mathrm{pH}$ 6.5), and distilled water was 10:10:9. The reaction mixtures were incubated at $25{ }^{\circ} \mathrm{C}$ for $15 \mathrm{~s}$. The absorbance of the mixture at $490 \mathrm{~nm}$ was measured using a microplate reader. The degree of inhibition of the sample was expressed as the concentration required for $50 \%$ inhibition $\left(\mathrm{IC}_{50}\right)$. One unit $(\mathrm{U})$ of enzymatic activity referred to the amount of an enzyme capable of converting $1 \mu \mathrm{M}$ of the L-tyrosine/L-DOPA reaction mixture within 1 min at $280 \mathrm{~nm}$ under the specific conditions $\left(25^{\circ} \mathrm{C}\right.$, optimum conditions).

\subsection{Enzyme Kinetic Analysis with Tyrosinase}

We observed the sample activity by decreasing the L-tyrosine (1.0, 0.5 , and $0.25 \mathrm{mM})$ substrate concentration to determine the tyrosinase inhibitory mechanism. The reaction mixture consisted of a $20 \mu \mathrm{L}$ test sample at the following test concentrations: 1.6, 8, and $16 \mu \mathrm{M}$ for MG; 10, 50, and $100 \mu \mathrm{M}$ for KG. Tyrosinase inhibition was determined at various concentrations of L-tyrosine substrate (1.0, 0.5, and $0.25 \mathrm{mM})$ in the absence or presence of the test compound concentrations $(1.6,8$, and $16 \mu \mathrm{M}$ for MG; 10, 50, and $100 \mu \mathrm{M}$ for $\mathrm{KG}$ ) using Lineweaver-Burk double reciprocal plots that determine enzyme kinetic parameters including $K_{m}$ and $V_{\max }$. The enzymatic procedures consisted of the previously described tyrosinase assay methods. The inhibition constant $\left(K_{i}\right)$ was determined from the interpretation of Dixon plots.

\subsection{Tyrosinase Molecular Docking Simulations}

The H-subunit (residues 2-392) of deoxy-form mushroom tyrosinase protein was obtained from the RCSB Protein Data Bank (ID: 2Y9X) [42]. Small molecules, including water, holmium 
(Ho) atoms, and tropolone, excluding copper (II) ions, were removed from the target enzyme. Binuclear copper-binding catalytic site of H-subunit of 2Y9X was slightly modified to fulfill the oxy-form enzyme [43]. All hydrogens were added. AutoDock 4.2 program was used to predict the ligand-protein interactions $[44,45]$. The copper ion parameters were prepared and added to run AutoGrid 4. The 3D structures of KG, MG, AB, L-tyrosine, kojic acid, and cinnamic acid were downloaded from PubChem Compound (NCBI), with compound CIDs of 5281667, 196583, 480819, 6057, 3840, and 444539, respectively. Kojic acid and cinnamic acid [34] were used as the reported catalytic and mixed type inhibitors against mushroom tyrosinase, respectively, and their binding sites were used to validate the results of AutoDock 4.2 docking analysis. The protein-ligand interactions were visualized and analyzed using PyMOL 1.7.4 (Schrodinger, LLC, Cambridge, MA, USA) for 3D models, and Discovery Studio Visualizer 16.1 (Accelrys, San Diego, CA, USA) was used for 2D diagrams.

\subsection{Statistical Analysis}

Differences between the control group and the test group were determined using Student's $t$-test (Sysat Inc., Evanston, IL, USA), and $P<0.05$ was used as a statistically significant cut-off value. All results were expressed as the mean \pm S.E.M. of triplicate experiments.

\section{Conclusions}

To sum up, KG and MG have attracted much interest in recent years, which inspired us to explore their potential cosmetic applications through computational studies and structural elucidation. In addition, we have examined the inhibitory activities of $K G, M G$, and $A B$ against both pathways of melanogenesis (monophenolase and diphenolase activities). Enzyme kinetic and computational assessment suggested that MG and KG were potent tyrosinase competitive inhibitors via H-bonding interaction with peroxide ion and van der Waals interaction with copper ions at the active site. This is the first report of MG, KG, and $\mathrm{AB}$ for enzyme kinetic mechanisms and molecular docking analysis to the best of our knowledge. The controversial inhibitory activity of KG has been resolved via kinetics and docking simulation studies, and the importance of the methyl cyclohexene functional group has been explored. Further studies of this moiety are necessary. Our results indicate that these active flavonoids might be promising candidates as cosmetic agents. However, further studies are needed to fully characterize the underlying mechanism responsible for the effects of KG and MG on murine or mammalian cell based assays.

Author Contributions: P.K. drafted the manuscript. S.H.S. performed the molecular docking studies. Y.Z. performed the enzyme assay and chemical kinetics. S.S. participated in the statistical analysis. H.A.J. and J.S.C. conceived the study and were also involved in the coordination of the study, and interpretation of the data. All authors read and approved the final manuscript.

Acknowledgments: This research was supported by the Basic Science Research Program through the National Research Foundation of Korea (NRF) funded by the Ministry of Science and ICT (2017R1A2B4005845).

Conflicts of Interest: The authors declare no conflict of interest.

\section{References}

1. Bagherzadeh, K.; Shirgahi Talari, F.; Sharifi, A.; Ganjali, M.R.; Saboury, A.A.; Amanlou, M. A new insight into mushroom tyrosinase inhibitors: Docking, pharmacophore-based virtual screening, and molecular modeling studies. J. Biomol. Struct. Dyn. 2015, 33, 487-501. [CrossRef] [PubMed]

2. Zeng, Q.; Chen, H.; Zhang, C.; Han, M.; Li, T.; Qi, X.; Xiang, Z.; He, N. Definition of eight mulberry species in the genus Morus by internal transcribed spacer-based phylogeny. PLoS ONE 2015, 10, e0135411. [CrossRef] [PubMed]

3. Kojima, Y.; Kimura, T.; Nakagawa, K.; Asai, A.; Hasumi, K.; Oikawa, S.; Miyazawa, T. Effects of mulberry leaf extract rich in 1-deoxynojirimycin on blood lipid profiles in humans. J. Clin. Biochem. Nutr. 2010, 47, 155-161. [CrossRef] [PubMed] 
4. Hussain, F.; Rana, Z.; Shafique, H.; Malik, A.; Hussain, Z. Phytopharmacological potential of different species of Morus alba and their bioactive phytochemicals: A review. Asian Pac. J. Trop. Biomed. 2017, 7, 950-956. [CrossRef]

5. Cui, X.Q.; Wang, H.Q.; Liu, C.; Chen, R.Y. Study of anti-oxidant phenolic compounds from stem barks of Morus yunanensis. J. Chin. Mater. Med. 2008, 33, 1569-1572.

6. Kobayashi, Y.; Miyazawa, M.; Araki, M.; Kamei, A.; Abe, K. Effects of Morus alba L. (Mulberry) leaf extract in hypercholesterolemic mice on suppression of cholesterol synthesis. Pharmacogn. Nat. Prod. 2015, 2, 1000113. [CrossRef]

7. Lee, J.S.; Kim, Y.R.; Park, J.M.; Kim, Y.E.; Baek, N.I.; Hong, E.K. Cyanidin-3-glucoside isolated from mulberry fruits protects pancreatic $\beta$-cells against glucotoxicity-induced apoptosis. Mol. Med. Rep. 2015, 11, 2723-2728. [CrossRef] [PubMed]

8. Ahmad, I.; Beg, A.Z. Antimicrobial and phytochemical studies on 45 Indian medicinal plants against multi-drug resistant human pathogens. J. Ethnopharmacol. 2001, 74, 113-123. [CrossRef]

9. Guo, C.; Yang, J.; Wei, J.; Li, Y.; Xu, J.; Jiang, Y. Antioxidant activities of peel, pulp and seed fractions of common fruits as determined by FRAP assay. Nutr. Res. 2003, 23, 1719-1726. [CrossRef]

10. Mallhi, T.H.; Qadir, M.I.; Khan, Y.H.; Ali, M. Hepatoprotective activity of aqueous methanolic extract of Morus nigra against paracetamol-induced hepatotoxicity in mice. Bangladesh J. Pharmacol. 2014, 9, 60-66. [CrossRef]

11. Chon, S.U.; Kim, Y.M.; Park, Y.J.; Heo, B.G.; Park, Y.S.; Gorinstein, S. Antioxidant and antiproliferative effects of methanol extracts from raw and fermented parts of mulberry plant (Morus alba L.). Eur. Food Res. Technol. 2009, 230, 231-237. [CrossRef]

12. Zheng, Z.P.; Cheng, K.W.; Zhu, Q.; Wang, X.C.; Lin, Z.X.; Wang, M. Tyrosinase inhibitory constituents from the roots of Morus nigra: A structure-activity relationship study. J. Agric. Food Chem. 2010, 58, 5368-5373. [CrossRef] [PubMed]

13. Chaita, E.; Lambrinidis, G.; Cheimonidi, C.; Agalou, A.; Beis, D.; Trougakos, I.; Mikros, E.; Skaltsounis, A.L.; Aligiannis, N. Anti-melanogenic properties of greek plants. A novel depigmenting agent from Morus alba wood. Molecules 2017, 22, 514. [CrossRef] [PubMed]

14. Abbas, G.M.; Abdel Bar, F.M.; Baraka, H.N.; Gohar, A.A.; Lahloub, M.F. A new antioxidant stilbene and other constituents from the stem bark of Morus nigra L. Nat. Prod. Res. 2014, 28, 952-959. [CrossRef] [PubMed]

15. Park, K.M.; You, J.S.; Lee, H.Y.; Baek, N.I.; Hwang, J.K. Kuwanon G: An antibacterial agent from the root bark of Morus alba against oral pathogens. J. Ethnopharmacol. 2003, 84, 181. [CrossRef]

16. Kuk, E.B.; Jo, A.R.; Oh, S.I.; Sohn, H.S.; Seong, S.H.; Roy, A.; Choi, J.S.; Jung, H.A. Anti-Alzheimer's disease activity of compounds from the root bark of Morus alba L. Arch. Pharm. Res. 2017, 40, 338-349. [CrossRef] [PubMed]

17. Guo, H.; Xu, Y.; Huang, W.; Zhou, H.; Zheng, Z.; Zhao, Y.; He, B.; Zhu, T.; Tang, S.; Zhu, Q. Kuwanon G preserves LPS-induced disruption of gut epithelial barrier in vitro. Molecules 2016, 21, 1597. [CrossRef] [PubMed]

18. Lee, H.J.; Ryu, J.; Park, S.H.; Woo, E.R.; Kim, A.R.; Lee, S.K.; Yeong, S.K.; Kim, J.O.; Hong, J.H.; Lee, C.J. Effects of Morus alba L. and natural products including morusin on In vivo secretion and In vitro production of airway MUC5AC mucin. Tuberc. Respir. Dis. 2014, 77, 65-72. [CrossRef] [PubMed]

19. Jung, H.W.; Kang, S.Y.; Kang, J.S.; Kim, A.R.; Woo, E.R.; Park, Y.K. Effect of kuwanon G isolated from the root bark of Morus alba on ovalbumin-induced allergic response in a mouse model of asthma. Phytother. Res. 2014, 28, 1713-1719. [CrossRef] [PubMed]

20. Geng, C.A.; Ma, Y.B.; Zhang, X.M.; Yao, S.Y.; Xue, D.Q.; Zhang, R.P.; Chen, J.J. Mulberrofuran G and isomulberrofuran $\mathrm{G}$ from Morus alba L.: Anti-hepatitis B virus activity and mass spectrometric fragmentation. J. Agric. Food Chem. 2012, 60, 8197-8202. [CrossRef] [PubMed]

21. Hong, S.; Kwon, J.; Kim, D.W.; Lee, H.J.; Lee, D.; Mar, W. Mulberrofuran G protects ischemic injury-induced cell death via inhibition of NOX4-mediated ROS generation and ER stress. Phytother. Res. 2017, 31, 321-329. [CrossRef] [PubMed]

22. Jung, J.W.; Ko, W.M.; Park, J.H.; Seo, K.H.; Oh, E.J.; Lee, D.Y.; Lee, D.S.; Kim, Y.C.; Lim, D.W.; Han, D.; et al. Isoprenylated flavonoids from the root bark of Morus alba and their hepatoprotective and neuroprotective activities. Arch. Pharm. Res. 2015, 38, 2066-2075. [CrossRef] [PubMed] 
23. Sohn, H.Y.; Son, K.H.; Kwon, C.S.; Kwon, G.S.; Kang, S.S. Antimicrobial and cytotoxic activity of 18 prenylated flavonoids isolated from medicinal plants: Morus alba L., Morus mongolica Schneider, Broussnetia papyrifera (L.) Vent, Sophora flavescens Ait and Echinosophora koreensis Nakai. Phytomedicine 2004, 11, 666-672. [CrossRef] [PubMed]

24. Zheng, Z.P.; Tan, H.Y.; Wang, M. Tyrosinase inhibition constituents from the roots of Morus australis. Fitoterapia 2012, 83, 1008-1013. [CrossRef] [PubMed]

25. Wu, T.; Qi, X.; Liu, Y.; Guo, J.; Zhu, R.; Chen, W.; Zheng, X.; Yu, T. Dietary supplementation with purified mulberry (Morus australis Poir) anthocyanins suppresses body weight gain in high-fat diet fed C57BL/6 mice. Food Chem. 2013, 141, 482-487. [CrossRef] [PubMed]

26. Hu, S.; Zheng, Z.; Chen, F.; Wang, M. The depigmenting effect of natural resorcinol type polyphenols Kuwanon O and Sanggenon T from the roots of Morus australis. J. Ethnopharmacol. 2017, 195, 196-203. [CrossRef] [PubMed]

27. Syah, Y.M.; Juliawaty, L.D.; Achmad, S.A.; Hakim, E.H.; Takayama, H.; Said, I.M.; Latip, J. Phenolic constituents from the wood of Morus australis with cytotoxic activity. Z. Naturforsch. C 2008, 63, 35-39.

28. Liao, Y.R.; Kuo, P.C.; Tsai, W.J.; Huang, G.J.; Lee, K.H.; Wu, T.S. Bioactive chemical constituents from the root bark of Morus australis. Bioorganic Med. Chem. Lett. 2017, 27, 309-313. [CrossRef] [PubMed]

29. Dalmagro, A.P.; Camargo, A.; Zeni, A.L.B. Morus nigra and its major phenolic, syringic acid, have antidepressant-like and neuroprotective effects in mice. Metab. Brain Dis. 2017, 32, 1963-1973. [CrossRef] [PubMed]

30. Souza, G.R; Oliveira-Junior, R.G.; Diniz, T.C.; Branco, A.; Lima-Saraiva, S.R.G.; Guimarães, A.L.; Oliveira, A.P.; Pacheco, A.G.M.; Silva, M.G.; Moraes-Filho, M.O.; et al. Assessment of the antibacterial, cytotoxic and antioxidant activities of Morus nigra L. (Moraceae). Braz. J. Biol. 2017. [CrossRef] [PubMed]

31. Chao, W.W.; Su, C.C.; Peng, H.Y.; Chou, S.T. Melaleuca quinquenervia essential oil inhibits $\alpha$-melanocyte-stimulating hormone-induced melanin production and oxidative stress in B16 melanoma cells. Phytomedicine. 2017, 34, 191-201. [CrossRef] [PubMed]

32. Zhang, L.; Zhao, X.; Tao, G.J.; Chen, J.; Zheng, Z.P. Investigating the inhibitory activity and mechanism differences between norartocarpetin and luteolin for tyrosinase: A combinatory kinetic study and computational simulation analysis. Food Chem. 2017, 223, 40-48. [CrossRef] [PubMed]

33. Cabanes, J.; Chazarra, S.; Garcia-Carmona, F. Kojic acid, a cosmetic skin whitening agent, is a slow-binding inhibitor of catecholase activity of tyrosinase. J. Pharm. Pharmacol. 1994, 46, 982-985. [CrossRef] [PubMed]

34. Hassani, S.; Haghbeen, K.; Fazli, M. Non-specific binding sites help to explain mixed inhibition in mushroom tyrosinase activities. Eur. J. Med. Chem. 2016, 122, 138-148. [CrossRef] [PubMed]

35. Loizzo, M.R.; Tundis, R.; Menichini, F. Natural and synthetic tyrosinase inhibitors as antibrowning agents: An update. Compr. Rev. Food Sci. Food Saf. 2012, 11, 378-398. [CrossRef]

36. Lee, S.Y.; Baek, N.; Nam, T.G. Natural, semisynthetic and synthetic tyrosinase inhibitors. J. Enzyme Inhib. Med. Chem. 2016, 31, 1-13. [CrossRef] [PubMed]

37. Slominski, A.; Zmijewski, M.A.; Pawelek, J. L-tyrosine and L-dihydroxyphenylalanine as hormone-like regulators of melanocyte functions. Pigment Cell Melanoma Res. 2012, 25, 14-27. [CrossRef] [PubMed]

38. Hyun, S.K.; Lee, W.H.; Jeong, D.M.; Kim, Y.; Choi, J.S. Inhibitory effects of kurarinol, kuraridinol, and trifolirhizin from Sophora flavescens on tyrosinase and melanin synthesis. Biol. Pharm. Bull. 2008, 31, 154-158. [CrossRef] [PubMed]

39. Yang, C.H.; Huang, Y.C.; Tsai, M.L.; Cheng, C.Y.; Liu, L.L.; Yen, Y.W.; Chen, W.L. Inhibition of melanogenesis by $\beta$-caryophyllene from lime mint essential oil in mouse B16 melanoma cells. Int. J. Cosmet. Sci. 2015, 37, 550-554. [CrossRef] [PubMed]

40. Masuda, T.; Odaka, Y.; Ogawa, N.; Nakamoto, K.; Kuninaga, H. Identification of geranic acid, a tyrosinase inhibitor in lemongrass (Cymbopogon citratus). J. Agric. Food Chem. 2007, 56, 597-601. [CrossRef] [PubMed]

41. Zheng, Z.P.; Chen, S.; Wang, S.; Wang, X.C.; Cheng, K.W.; Wu, J.J.; Yang, D.J.; Wang, M. Chemical components and tyrosinase inhibitors from the twigs of Artocarpus heterophyllus. J. Agric. Food Chem. 2009, 57, 6649-6655. [CrossRef] [PubMed]

42. Ismaya, W.T.; Rozeboom, H.J.; Weijn, A.; Mes, J.J.; Fusetti, F.; Wichers, H.J.; Dijkstra, B.W. Crystal structure of Agaricus bisporus mushroom tyrosinase: Identity of the tetramer subunits and interaction with tropolone. Biochemistry 2011, 50, 5477-5486. [CrossRef] [PubMed] 
43. Maria-Solano, M.A.; Ortiz-Ruiz, C.V.; Munoz-Munoz, J.L.; Teruel-Puche, J.A.; Berna, J.; Garcia-Ruiz, P.A.; Garcia-Canovas, F. Further insight into the $\mathrm{pH}$ effect on the catalysis of mushroom tyrosinase. J. Mol. Catal. B Enzym. 2016, 125, 6-15. [CrossRef]

44. Goodsell, D.S.; Morris, G.M.; Olson, A.J. Automated docking of flexible ligands: Applications of AutoDock. J. Mol. Recognit. 1996, 9, 1-5. [CrossRef]

45. Seong, S.H.; Ali, M.Y.; Kim, H.R.; Jung, H.A.; Choi, J.S. BACE1 inhibitory activity and molecular docking analysis of meroterpenoids from Sargassum serratifolium. Bioorganic Med. Chem. 2017, 25, 3964-3970. [CrossRef] [PubMed]

Sample Availability: Tested compounds (kuwanon G, mulberrofuran G, and albanol B) are available from the authors.

(C) 2018 by the authors. Licensee MDPI, Basel, Switzerland. This article is an open access article distributed under the terms and conditions of the Creative Commons Attribution (CC BY) license (http:// creativecommons.org/licenses/by/4.0/). 